\title{
Effects of Electronic Reading Environments' Structure on L2 Reading Comprehension
}

\author{
Khalid Al-Seghayer ${ }^{1}$ \\ ${ }^{1}$ College of Languages and Translation, Al Imam Mohammad Ibn Saud Islamic University, Saudi Arabia \\ Corresponding: Khalid Al-Seghayer, College of Languages and Translation, Al Imam Mohammad Ibn Saud \\ Islamic University, Saudi Arabia. E-mail: alseghayer@yahoo.com
}

Received: September 20, 2017

Accepted: November 6, 2017 Online Published: November 8, 2017

doi: $10.5539 /$ elt.v10n12p88

URL: http://doi.org/10.5539/elt.v10n12p88

\begin{abstract}
This study examines the effects of an electronic reading environment's structure on second language (L2) reading comprehension. In particular, this study explores whether clarifying the underlying structure of an electronic text, along with the ways in which its units or nodes are organized and interrelated results in better comprehension as well as whether L2 reading proficiency affects the comprehension of electronic text. In this study, 40 English as a second language (ESL) learners, grouped into proficient and less-proficient groups based on their scores on the Test of English as a Foreign Language's (TOEFL's) Reading section, were asked to read two electronic texts using computerized programs classified as either "well structured" or "less structured." To assess the efficacy of each type of reading environment, two tests - a multiple-choice test and a mapping of main ideas and details (MOMID) test - were developed and administered to the participants after they read each text. The results of these tests were analyzed using a paired-samples $t$-test and a two-way (proficiency level by computerized reading program) mixed-model analysis of variance (ANOVA). The findings revealed that well-structured electronic texts can aid ESL readers in developing a more coherent mental representation of the electronic texts' content, thereby increasing their reading comprehension. Furthermore, well-structured electronic texts are more helpful for less-proficient readers than for more-proficient readers. These findings have significant pedagogical and technological implications for $\mathrm{L} 2$ reading instructors and instructional designers.
\end{abstract}

Keywords: electronic reading environment, L2 reading comprehension, structure of an electronic text, L2 reading proficiency

\section{Introduction}

In electronic environments, reading materials are often nonlinear and do not follow a specific order. Accordingly, readers play a more active role in deciding what to read next, browse, and search for; figuring out the semantic relationships among text units; and integrating information from various text segments. To build a detailed representation of electronic content at the local level while also developing a more general representation of a text's global meaning, readers must implement more complex processes and choices and utilize features specific to that electronic text. Unfortunately, when faced with an unfamiliar text structure and a lack of clear textual context, many readers, particularly English as a second language (ESL) readers, become lost and fail to obtain an overview of the document as a whole. Thus, current electronic text formats often lead to text-integration issues, or cohesion deficit, which greatly affects reading comprehension.

Despite the prevalence of electronic text in language learning classrooms, the factors that influence a student's ability to build a mental representation of electronic content, which is required for comprehension, have not been thoroughly explored. Moreover, little empirical research has been done on the effects of providing visual and verbal conceptual orientation to an electronic text's structure, at both the local and global levels, on reading comprehension. In particular, the potential effect on second language (L2) reading comprehension of providing structural cues in an electronic text has yet to be examined.

This situation introduces an important question: Would a well-structured electronic reading environment enable ESL readers to overcome potential difficulties in integrating information and building a unified representation of text content delivered by computer? To address this question, this study examines the effect of embedded interactive microstructural and macrostructural visual and verbal organizational devices on electronic text comprehension. This study also analyzes the interaction between L2 reading proficiency and the degree of 
structure in an electronic text as ESL learners develop coherent mental representations of electronic content, which facilitate reading comprehension. In other words, this study also investigates the relationship between L2 readers' proficiency and the presence or absence of organizational devices in learners' electronic reading comprehension.

This study adds to the general body of knowledge in Computer-Assisted Language Learning (CALL) and to L2 computerized reading by determining what effect, if any, the presence of organizational cues has on L2 reading comprehension of the electronic text content, as well as identifying factors that may influence comprehending electronic text. Verification of such factors will help L2 reading program designers create effective electronic reading environments and provide a better understanding of the nature of the cognitive aspects involved in reading electronic texts.

\subsection{Literature Review}

The conceptual framework underlying this study combines three theoretical perspectives: (a) the construction-integration model of reading comprehension (Kintsch, 1998; Kintsch \& van Dijk, 1978) and the documents model of multiple text integration (Britt et al., 2013; Perfetti et al., 1999; Rouet, 2006), (b) the new literacies theory of online reading, and (c) online reading comprehension. Concepts derived from these three theoretical frameworks were applied to explore the effects of an electronic reading environment's structure and organizational devices on $\mathrm{L} 2$ reading comprehension.

The first perspective that informs this study is derived from the construction-integration model of reading comprehension and the documents model of multiple text integration. These models suggest that readers construct a model of understanding for a single text by building a text base and then a situation model for the text.

The second theoretical perspective is a new literacies paradigm, which indicates that the nature of literacy changes as new technology emerges (Alexander \& Jetton, 2000; Coiro \& Dobler, 2007). According to the new literacies perspective, digital and electronic readers need to know and be aware of new electronic reading strategies to recognize and generate important questions and locate, critically evaluate, and synthesize information found in the electronic environment (Castek et al., 2007; Coiro \& Dobler, 2007; Leu et al., 2007). These essential processes in electronic reading also inform readers' ability to communicate information (Leu et al., 2007). As Coiro (2003) predicted, proficiency in the new literacies of the electronic reading environment has become essential to our students' future learning.

The third perspective concerns the issue of electronic reading comprehension. According to Coiro and Dobler (2007), online reading involves the use of offline reading comprehension skills but is more complex and requires many additional skills. These include engaging in self-directed text construction (to avoid the cognitive overload and disorientation often experienced by electronic text readers), employing a more complex dimension of inferential reasoning strategies to construct meaning, and constructing meaning through flexible and purposeful choices of available electronic formats. The remainder of this literature review will explore these issues in greater detail, particularly in relation to the ESL context.

\subsection{Comprehension and the Electronic Reading Environment}

Given the changing nature of reading environments, researchers have generated a variety of constructs with which to describe reading within digital contexts. For example, Kintsch and van Dijk (1978) and van Dijk and Kintsch (1983) proposed that electronic documents are understood through macrostructural processing, or the application of a set of macrorules that enable readers to build coherent mental representations. There are two important factors in macrostructural processing: (a) macrostructural construction, which entails selecting and extracting important textual information from individual units, and (b) macrostructural organization, which involves integrating selected information into a coherent representation by connecting semantic links. In other words, comprehension of electronic texts requires two distinct levels of macrostructural processing: construction and organization.

Local (construction) and global (organization) macrostructural representations are results of the electronic environment's effect on macroprocessing. As discussed above, the distinctive manifestation of processes common to offline reading comprehension - such as locating, analyzing, synthesizing, and communicating - make electronic reading more complex than traditional reading (Coiro \& Dobler, 2007; Leu et al., 2008). Readers must select a designated unit, read it, and integrate its contents, which involves Kintsch and van Dijk's (1978) construction macrorules. Readers must also choose from different possible links and texts.

For readers to comprehend an electronic text successfully, they should first identify the interrelationships among 
text units and then organize the macrostructural representations of all units into a coherent representation. Textual factors, such as the use of headings and the marking of important information, foster macrostructural construction (Foltz, 1996). However, readers also need the ability and skills to flexibly integrate existing knowledge structures with new knowledge applications in new reading situations (Spiro, 2004).

L2 electronic reading provides a context for the current study. For instance, Kim (2007) examined the effects of computer-assisted reading instruction on L2 reading comprehension. In this study, 66 Korean EFL learners were able to comprehend the provided electronic text, indicating that electronic texts help to facilitate L2 readers' reading comprehension. Similarly, Abdi (2012) reported that EFL learners demonstrated greater reading comprehension ability when working with digital materials as compared to nondigital materials, and Salkhord, Gorjian, and Pazhakh (2013) found that, compared to paper-based stories, Internet-based digital stories had the greatest effect on EFL learners' reading comprehension as well as a better effect on their memory and retention.

With respect to meaning construction in electronic reading environments, according to Park, Yang, and Hsieh (2014), L2 readers' employ considerable prior knowledge of the structure of both offline and online resources to aid in their online reading comprehension. Additionally, they follow a recursive pattern of self-regulated reading strategies when they construct meaning while reading electronic texts. Textual factors can further support this construction of meaning. For example, in Liu's (2015) study, 72 EFL learners read an English e-book with various comprehension cues and under different input presentation modes. The results showed that the participants were better able to comprehend and retain digital content in a cognitively challenging (simultaneous) electronic reading environment.

Investigating the effect of specific textual features, Al-Seghayer (2007) examined the efficacy of embedding microstructural devices (headings, reviews, and logical connective statements) and macrostructural devices (a graphical overview of the text content) into the construction and organization of electronic text presentations. Al-Seghayer found that well-structured electronic texts aided ESL readers in developing a more coherent mental representation of the electronic content. In a similar vein, Yanguas (2009) found that the addition of glosses (textual, pictorial, and combined textual and pictorial) to an electronic text helped students comprehend reading passages far better. In particular, combination glosses were the most beneficial for reading comprehension.

With respect to specific computerized reading programs, Alshumaimeri and Almasri (2012) determined that WebQuests (inquiry-oriented lessons that use online resources) had a positive effect on Saudi EFL students' reading comprehension. According to Alshumaimeri and Almasri, WebQuests improve participants' reading comprehension because they require analysis, synthesis, evaluation, judgment, problem solving, and creativity. The unique nature of learning via WebQuests, which emphasize constructivist learning that incorporates critical thinking and knowledge application, also makes this program particularly useful.

Despite these positive findings, Chiang's (2016) study on electronic reading environments challenges the benefits of electronic text for ESL reading comprehension. In this study, Chiang found that the use of an electronic reading device did not improve participants' reading comprehension. In fact, Chiang proposed that electronic reading environments may prevent ESL readers from using their analytical skills to gain meaning from a text, which may impede their reading comprehension.

\subsection{ESL Reading Abilities in Electronic Reading Environments}

As Chiang's (2016) findings suggest, other factors beyond simply digital versus nondigital are believed to influence the extent to which readers can construct a coherent mental representation of electronic text content and thus fully comprehend the content. In particular, various empirical studies have examined the influence of reading proficiency variables on reading comprehension in electronic reading environments. For example, Zwaan and Brown (1996) contended that comprehending electronic text requires sufficient lexical and syntactic processing skills as well as an ability to generate explanatory inferences. Therefore, less-skilled readers - especially L2 learners-lack the necessary skills to develop a coherent mental representation in electronic reading environments.

Moreover, readers approach electronic text systems differently based on their reading abilities; thus, user characteristics can contribute to the success or failure of learners' reading experiences, both in general and in an electronic reading environment. To examine the influence of these characteristics, some studies have focused on aspects of individual differences related to organizing and processing information (Lee, 1989; Leidig, 1992; Nielsen, 1989). Others have studied factors such as readers' comprehension skills, domain knowledge, motivation, and language abilities (Zwaan \& Brown, 1996).

Various studies have also examined these issues from cognitive and metacognitive perspectives and thereby 
investigated the interaction between readers' abilities and electronic text features. Such an approach is well founded in text-processing theories and empirical evidence. However, these studies have produced mixed results, as will be explained shortly.

For example, Balajithy (1990) investigated how readers, especially less-skilled readers, interact with features of electronic text and found that the control over reading pace that a computer usually gives readers benefits skilled readers more than it does less-skilled readers. When they are able to control the pace, skilled readers can utilize their own reading strategies, which less-skilled readers lack. At the same time, the high degree of user control over electronic text negatively affects less-skilled readers' comprehension because, unlike skilled readers, they are unable to exert active control over the reading.

Adopting a slightly different approach, Leidig (1992) investigated the relationship between cognitive style (learning styles and spatial ability) and structural maps in an electronic reading environment. Participants completed a spatial ability test and were then categorized into one of four learning styles: (a) divergers, (b) assimilators, (c) convergers, or (d) accommodators. Leidig's findings demonstrated a significant interaction between learning styles and structural maps. In this case, assimilators performed well with both textual and graphical maps of the electronic text's structure, whereas convergers and accommodators were less effective under similar conditions.

In a related study, Balcytiene (1999) examined individual processes of knowledge construction when reading electronic text. Instead of comparing printed text and electronic text, Balcytiene attempted to study the influence of electronic text on knowledge acquisition by examining readers' patterns of electronic text-reading strategies and the role of individual differences within electronic reading environments. Thirty-eight undergraduates were randomly assigned to one of two treatments: 23 participants read printed text, and 15 participants read electronic text. Learning outcomes were measured using pretest and posttest questionnaires. Based on their electronic reading behavior, the participants were classified as either self-regulated or cue-dependent readers. Self-regulated readers seemed to benefit more from electronic reading environments because they (a) were more capable of using their metacognitive skills, (b) experienced less test anxiety, and (c) were globally oriented in terms of information access strategies, meaning that, from the onset, they retrieved significant information for the initial construction of a mental model, which was later explained. In contrast, the cue-dependent readers had a local orientation and reacted to the topical demands of a particular guiding question.

McNamara et al. (1996) found comparable results when they examined the role of text coherence in the comprehension of science texts. In this case, a well-developed, structured reading environment improved the comprehension of readers with low prior knowledge and impaired the comprehension of those with high prior knowledge. McNamara et al. justified the results by proposing that a well-developed structure would reduce the amount of active processing assumed by skilled (knowledgeable) readers.

However, Hofman and Oostendorp (1999) obtained contradictory results. Unlike McNamara et al. (1996), Hofman and Oostendorp found that very well-structured electronic environments hindered the comprehension of readers with low prior knowledge. According to Hofman and van Oostendorp, a well-developed global structure provided by a structural overview distracts less-skilled readers from the local structure of a text. Developing a mental representation of electronic text largely depends on the reader's ability to keep track of the local semantic relationships between propositions. If electronic reading environments do not make these relationships salient to readers, those with low knowledge cannot derive such local semantic relationships from their prior knowledge. Conversely, in the absence of an overt local structure, skilled readers can derive semantic relationships between propositions from their own background knowledge.

Readers' proficiency level can also influence which metacognitive online reading strategies they use. In Pookcharoen's (2009) study, 111 Thai EFL students from various majors responded to 28 items on an online reading strategy survey and an Internet use questionnaire set for pre- and post-reading. They also participated in interviews and engaged in think-aloud sessions and self-reports of online reading strategies. Pookcharoen found differences between the proficient and less-proficient readers in terms of their utilization of metacognitive online reading strategies. Specifically, the proficient readers reported using problem-solving strategies the most, global strategies second most, and support strategies the least, whereas the less-proficient readers used problem-solving strategies the most, followed by support strategies and global strategies.

In contrast, Songsiengchai (2010) found no difference in the use of online reading strategies between 73 highand low-proficiency third-year English major students. The participants completed a questionnaire on reading strategies for reading online academic texts and a questionnaire on reading strategies for printed academic texts. Although proficient readers used metacognitive strategies at a higher level for printed texts, both proficient and 
less-proficient readers used reading strategies for online texts at a medium level.

Al-Seghayer (2014) adopted a similar perspective to identify the metacognitive online reading strategies that both proficient and less-proficient ESL learners apply when reading electronic English texts. The results indicated that these learners did not differ significantly regarding the degree to which they reported using global and problem-solving online reading strategies.

Overall, the literature clearly illustrates that constructing a coherent mental representation of electronic text largely depends on two factors: (a) readers' abilities and (b) how well the electronic reading environment is structured. Hence, there is a clear relationship between readers' abilities and the structural elements employed in an electronic text system. Although the extent of readers' needs to develop an integrated representation seems to differ-for instance, skilled readers are still capable of developing the required coherent representation when using ill-structured electronic text systems, but less-skilled readers cannot build similar representations-both skilled and less-skilled readers need to be situated in a very well-structured electronic reading environment.

\subsection{Overview of the Current Study}

In the digital age, a large amount of reading is done in an electronic or screen-based, rather than paperbound environment; therefore, electronic texts play a role in a wide range of everyday situations. Electronic texts are also an increasingly significant source of input for ESL learners, as they spend more time reading electronic texts over the Internet on computers, laptops, mobile devices, e-books, tablets, and other handheld devices, all of which offer a broad range of interactive learning features. However, although there has been an explosion of research related to digital or online reading, no current studies explore the relationship between reading proficiency and electronic reading comprehension. Additionally, studies on computer-based L2 reading environments have not explicitly probed the effect of the structural environment on ESL students' reading comprehension.

Accordingly, the current study fills this gap in the literature by determining whether embedding organizational devices into an electronic text that outline the underlying structure of the text and explain how it is organized would help L2 readers to better comprehend the text's contents. This study also explores the effect of English reading proficiency levels on learners' comprehension of well-structured versus less-structured electronic texts. Thus, focusing on electronic reading comprehension and reading proficiency, this study considers two guiding questions: Does the degree of coherence (that is, good structuring) in computerized reading programs positively affect ESL learners' reading comprehension?

Are there interaction effects between L2 readers' reading proficiency and the degree of structuring of computerized reading programs on sESL learners' reading comprehension? To answer these questions, this study tests the following hypotheses: ESL learners' electronic reading comprehension will be stronger when using a well-structured computerized reading program than when using a less-structured program. The reading comprehension outcome of proficient ESL readers will remain the same under both treatment conditions, whereas in the case of less- proficient readers, it will be significantly better in the well structured electronic environment than in the less-structured electronic environment.

\section{Materials and Methods}

\subsection{Participants}

The participants (17 women and 13 men) in this study were ESL students from 10 different language backgrounds enrolled in the English Language Institute (ELI) at a Midwestern U.S. research university (see Table 1) who ranged in age from 19 to 40 . At the time of the data collection, these students were receiving 20 hours of intensive weekly instruction for 14 weeks. Their academic backgrounds reflected a variety of majors, and all of them were planning to enroll in undergraduate or graduate studies after they passed the language requirements.

To qualify for the study, each participant had to have spent at least two semesters in the host environment and attained a Test of English as a Foreign Language (TOEFL) score of 450-530 (intermediate). Each student also had to be placed in Level 4-the intermediate level - based on their performance on the reading section of the institution's placement test (the Michigan Test), on which they had to score around 60 (out of 100 points). The participants' instructors were asked to confirm each participant's intermediate proficiency level in reading.

As this was a mixed-design study, all of the participants were exposed to the same treatment conditions. The participants had different language backgrounds; however, each participant served as his or her own control. Therefore, their different language backgrounds were controlled. 
Intermediate-level ESL learners were chosen because they could handle texts from a more global perspective and knew enough vocabulary and grammar to understand the texts used in this study. However, this sample of intermediate-level learners included readers with different levels of proficiency. Based on their scores on the TOEFL reading section, the participants were divided into two categories: proficient (score of 35-54) and less proficient (score of 15-20). The proficient group included 15 women and 5 men with aged 19 to 40 years. The native languages of the students in this group were Chinese (5), Japanese (4), Korean (4), Arabic (2), Spanish (2), Swedish (1), Thai (1), and Turkish (1); 16 were graduate students, and four were undergraduate students. The less-proficient group included 12 women and eight men ranging in age from 20 to 33. The native languages represented in this group were Japanese (6), Arabic (5), Chinese (2), Spanish (2), Thai (2), Italian (1), Korean (1), and Turkish (1); 14 were graduate students, and six were undergraduate students.

Table 1. Participant characteristics

\begin{tabular}{lccc}
\hline Country of origin & Male & Female & Total \\
\hline Bahrain & - & 2 & 2 \\
China & 1 & 2 & 3 \\
Japan & 2 & 8 & 10 \\
Italy & - & 1 & 1 \\
Lebanon & - & 1 & 1 \\
South Korea & 2 & 3 & 5 \\
Morocco & - & 1 & 1 \\
Mexico & 1 & - & 1 \\
Qatar & 3 & - & 3 \\
Peru & - & 1 & 1 \\
Sweden & - & 1 & 1 \\
Taiwan & 1 & 3 & 4 \\
Thailand & 2 & 1 & 3 \\
Turkey & - & 2 & 2 \\
Venezuela & 1 & 1 & 2 \\
\hline Total & 13 & 27 & 40 \\
\hline
\end{tabular}

\subsection{Setting}

All of the sessions took place at the Language Media Center at a Midwestern U.S. research university. The center had 44 computers, and most of the ELI students used this computer lab for school assignments and other related computing needs.

\subsection{Design}

In this mixed-design study, the participants served as their own controls. The between-subject factor was reading ability, with two levels of proficiency (high and low), and the within-subjects factor was the use of organizational devices at two levels (presence or absence of organizational devices). The participants read two analogous electronic texts - the first with an organizational device and the second without - and then took two tests for each text: a multiple-choice test and a mapping of ideas and details (MOMID) test.

The independent variables-well-structured and less-structured computerized reading programs-were experimentally manipulated by exposing the participants to both treatment conditions. The dependent variables - reading comprehension and the construction of mental representations of the electronic texts at the local and global levels-were measured using two different reading tests (see Table 2). 
Table 2. Study design

\begin{tabular}{lll}
\hline Reading ability & $\begin{array}{l}\text { Text with organizational devices } \\
\text { included }\end{array}$ & $\begin{array}{l}\text { Text without organizational devices } \\
\text { included }\end{array}$
\end{tabular}

Proficient readers

Less-proficient readers

\subsection{Procedures}

The experimental procedures consisted of three phases conducted over the course of four meetings. The first phase lasted $1 \mathrm{hr} 35 \mathrm{~min}$ and served as an introductory session wherein the participants, either individually or in small groups, met with the researcher at the Language Media Center. Each participant was informed about the purpose of the study and asked to fill out an informational background questionnaire and take the TOEFL test.

The second phase lasted approximately $30 \mathrm{~min}$ and served as a practice session in which the participants received a brief introduction to the computerized reading programs and practice reading texts similar to the experimental ones.

The third and final phase lasted $2 \mathrm{hr}$ and was conducted in two separate 1-hr meetings that served as the experimental sessions. In each meeting, the participants were asked to (a) read two analogous expository electronic texts on a computer screen under two different conditions, one with organizational devices included and one without (30 min each); (b) take comprehension tests (10-15 min each); and (c) sit for a short interview (15-20 minutes). The participants completed all of the tasks within a 4-hr block of time.

To avoid any potential order effect, the order of the passages was varied and counterbalanced. The first 10 proficient readers read the electronic text without organizational devices and took the tests associated with the text; the other 10 read the electronic text with organizational devices and completed the associated tests. The tasks were then repeated with the other text. Likewise, the first 10 less-proficient readers read the electronic text with organizational devices and took the tests associated with it; the remaining 10 read the electronic text without organizational devices and completed the associated tests. The tasks were then switched.

\subsection{Instructional Materials}

\subsubsection{Reading Passages}

Two passages were selected from the undergraduate textbook Sociology: Experiencing Changing Societies (Kammeyer, Ritzer, \& Yetman, 1997). The two passages, "Human Interaction" (HI) and "Verbal Symbols and Language" (VSL), were expository in nature and judged to be unfamiliar to most intermediate-level students. The passages were selected according to seven specific criteria: the texts (a) shared the same subject matter, (b) shared the same literary style, (c) shared the same length, (d) shared the same degree of difficulty, (e) were authentic passages, (f) required minimal background knowledge, and (g) had a logical rhetorical ordering of ideas.

The selected passages had appropriate syntactic complexity for intermediate ESL learners because they consisted of short, uncomplicated sentences. The mean length of the sentences was 20.0 words in HI and 19.5 in VSL, and the percentage of simple sentences was $44 \%$ in HI (18 out of 41 ) and $44.4 \%$ in VSL (16 out of 33). By contrast, the percentage of complex sentences was $17 \%$ in HI (7) and $12 \%$ in VSL (4), while that of compound sentences was 39\% in HI (16) and 39\% in VSL (13). The high percentage of simple sentences made the texts appropriate for intermediate ESL learners; because the passages did not contain complicated grammatical constructions, readers at this level presumably would not have difficulty reading and understanding them.

The text difficulty of both texts was examined using the Lix formula, a readability formula recommended by Schultz (1981) for analyzing foreign texts. Readability was calculated by dividing the number of words in each reading passage by the number of sentences and adding that total to the number of long words (words over six letters) multiplied by 100 and divided by the number of words in the passage. As shown in Table 3, the Lix averages, or readability, for both texts were close: 22.50 for HI and 19.32 for VSL. 
Table 3. Lix readability formula

\begin{tabular}{lllllllll}
\hline Text & \# of words & \# of sentences & $\begin{array}{l}\text { Words } \\
\text { sentence }\end{array}$ & per & $\begin{array}{l}\text { Words over } 6 \\
\text { letters }\end{array}$ & D + E & F x 100 & Lix \\
\hline HI & 900 & 40 & 22.50 & 180 & 202.50 & 20250 & 22.50 \\
VSL & 850 & 35 & 24.28 & 140 & 164.28 & 16428 & 19.32 \\
\hline
\end{tabular}

\subsubsection{Consulting with Reading Teachers}

Two ESL reading teachers assisted with designing the organizational devices included in the computerized reading programs. The teachers were asked to suggest the best global and local titles for each unit, write statements connecting each text unit to the next, and write a short preview for each unit. They also performed idea unit analyses on the texts by identifying one main idea and two supporting ideas for each paragraph.

\subsubsection{Converting the Selected Texts into Electronic Documents}

The two experimental passages were converted into electronic documents. Each of the eight paragraphs in the two texts served as a single unit that filled part of the screen, along with the associated local and global titles, a review of the unit, an overview map (well-structured program), and an alphabetized list of the text content (less-structured program). The content, length, and syntactical structure of the paragraphs were left unchanged. Thus, there were eight units that each could stand alone. The participants could move among them using links. In the case of the HI text, the participants could click on the overview map titles to display the content of the selected unit on the screen along with the included organizational devices. In the VSL text, they could click on the titles in an alphabetical list to display the content of the selected unit on the screen.

\subsubsection{Computerized Reading Program: Content and Organization}

The researcher designed two computerized reading programs (well structured and less structured) with similar introductory sections and aesthetics but different main sections. The programs' designs were based on principles proposed by Leshin, Pollock, and Reigeluth (1992) and Thorn (1995). Both computerized reading programs, along with their tests, were developed using Flash MX (2002) software. The audio component was recorded and processed using Digital Performer 3.02 (MOTU, 2001).

Each program contained a tutorial, an introduction, and a main section. The tutorial illustrated how to interact with the screen features and use the program effectively. In the well-structured program, the tutorial instructions also encouraged participants to use the structure of the electronic text to guide their reading. The introduction previewed the electronic texts and explained that each text was divided into units displayed independently on the computer screen. The tutorial and introduction were included to reduce the cognitive load imposed by the new instructional environment and to ensure that participants who were less familiar with reading electronic text were not disadvantaged.

\subsubsection{Well-structured Computerized Reading Program}

The well-structured computerized reading program contained the HI text. After the tutorial and introduction, the users saw a static global overview of the unit titles organized hierarchically and displayed as interconnected semantic nodes along with an explanation of the overview map's function and organization. The window displaying the actual text was divided into three frames: a title banner across the top, the overview map on the left, and the actual text. The frame containing the actual text included the local and global headings of each unit and two navigation buttons: previous and review. The previous button let the users return to the previously visited point, and the review button displayed a brief preview of the unit's content (see Figure 1). 


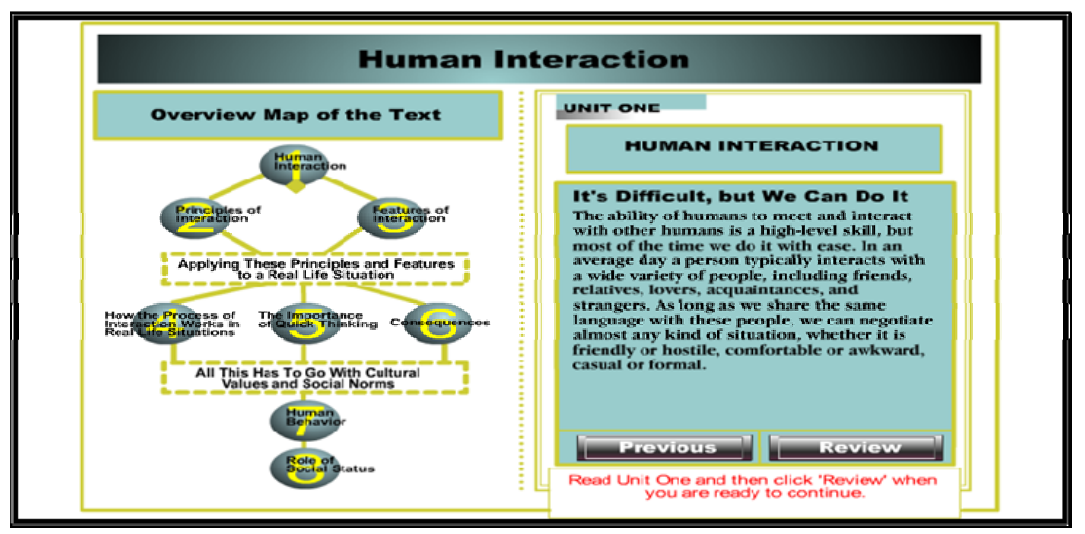

Figure 1. Screenshot of the main section of the well-structured computerized reading program

The actual text was divided into eight standalone units, each consisting of an 80- to 110-word paragraph from the original text. The readers could move among the units by using the links on the overview map. Instructions on how to interact with the program's features were placed at the bottom right of each page. Upon completing the final unit, the users had the opportunity to see all of the text presented in every unit and then return to the overview page. A message informed the users that they could review any of the units.

\subsubsection{Less-structured Computerized Reading Program}

After viewing a brief introduction to the program, the participants saw some unstructured electronic text similar to the unstructured, menu-like list of unit titles that readers would typically encounter in an instructional electronic environment. The list overview, which filled the whole screen, presented the major topics and segments of the selected text without indicating the relationships among them.

The second section of this program contained the VSL text divided into smaller paragraph units so that each could stand alone, and each unit had a title reflecting its contents. The window that displayed the text was divided into three frames. The top frame showed the title of the text, the left frame displayed the list-like overview showing the main units comprising the text, and the bottom of the right frame contained the navigation buttons. On the right frame, the button on the lower right took users to the next unit, and the button on the left corner allowed users to return to the previous unit (see Figure 2).

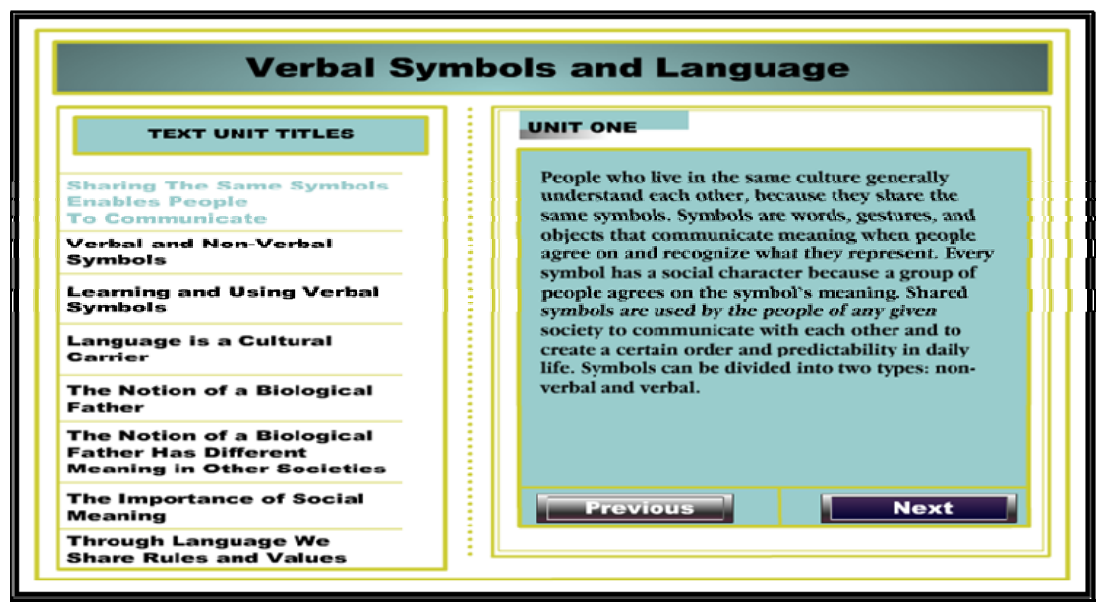

Figure 2. A screenshot for the less-structured computerized reading program

\subsection{Evaluation Measures}

The evaluation measures were selected to (a) reflect the degree to which a text was represented at the global level, (b) test knowledge of text structure (using a MOMID test), and (c) test how the experimental manipulations affected recognition of text information (using a multiple-choice test). In addition, the measures were designed primarily to assess knowledge of concept relationships rather than simple knowledge of facts or 
ideas. Production assessments such as free or cued written recall were avoided because it was assumed that the participants' writing ability was not adequately developed to express their thoughts.

Reading comprehension was tested using multiple-choice test items. Each multiple-choice test had 15 questions, and each question listed four possible answers. To produce an accurate measure of the amount of material learned, the construction of the multiple-choice items considered several issues: (a) passage dependency, (b) the breadth of coverage of test items, (c) an absence of response cues, (d) the plausibility of distractors, $€$ careful wording, and (f) randomization.

After reading each electronic text, the participants clicked on the "Begin Quiz" button, which took them directly to the associated multiple-choice test. Introductory instructions and instructions accompanying each question made the test taking less confusing, reduced the chance of error, and allowed for an accurate measure of the time the users spent on each question. Because the questions required them to either integrate information or infer something that was not explicitly expressed in the texts, the participants were permitted to look at the electronic text while answering the questions. Once they were finished, they submitted their answers by clicking the "Submit" button. Their answers, along with their background information, were automatically sent to the investigator's researcher's e-mail account and database management file.

After completing the multiple-choice test, the participants proceeded to a take a MOMID test that examined their sensitivity to the text structure. The instructions for this test were presented in an initial window. Each MOMID test consisted of a list of 24 sentences that included both main ideas and details taken randomly from the electronic text units. The participants were asked to identify each sentence as either the main idea or a detail of a given unit and indicate its status on a map. Because the questions required them to infer or locate main ideas and detailed information that were not explicitly expressed in the texts, the participants could look at the electronic texts while answering the questions. This test was constructed in consultation with ESL reading experts and was subject to several considerations, including (a) limited alternatives, (b) an absence of response cues, (c) the plausibility of distractors, (d) careful wording, a€(e) randomization. Once they completed the MOMID test, the participants submitted their answers by clicking the "Submit" button. Their answers, along with their background information, were automatically sent to the researcher's email account and database management file. Upon completion, the participants received a message that thanked them for their participation and indicated that their data had been received.

\subsection{Test Item Analysis}

Item analysis for the multiple-choice tests revealed a difficulty index ranging from 0.55 to 0.92 for the well-structured program's test and from 0.33 to 0.80 for the less-structured program's test. For the multiple-choice test used with the less-structured program, the index of discriminability ranged from and 0.20 to 0.45 .

For the MOMID tests, the index of difficulty ranged from 0.52 to 71 for the well-structured program's test and from 0.36 to 60 for the less-structured program's test. For the MOMID test used with the less-structured program, the index of discriminability ranged from 0.20 to 0.50 .

The internal consistency reliability of the tests was estimated from a single administration of the tests using the Kuder-Richardson formula. The internal consistency reliability estimates of the multiple-choice tests used for the well-structured and less-structured programs were 0.74 and 0.72 , respectively. The internal consistency reliability estimates of the MOMID tests used for the well-structured and less-structured programs were 0.70 and 0.68 , respectively.

\subsection{Scoring System for the Employed Test}

All of the tests were discrete-point tests, so each test was scored following similar procedures. For the multiple-choice tests, each correct answer received one point. An incorrect answer received zero points. For the MOMID tests, full credit was awarded for assigning all ideas correctly, and one point was deducted for each mistake. The test answers were routed electronically to a MySQL database with the help of customized PHP code. This enabled the quiz and tracking results to be sent directly to the researcher's e-mail address for evaluation.

\subsection{Data Analysis Procedures}

The collected data were subjected to statistical descriptive analysis. Inferential statistics were used to predict the characteristics of similar sets of data, thereby revealing how generalizable the results were to the whole population of ESL learners. 
A paired samples $t$-test was conducted on the participants' scores for specific questions developed to examine the participants' ability to extract the main idea of the well-structured and less-structured electronic texts as well as measure their reading comprehension under both conditions. The results were further analyzed using a two-way mixed-model ANOVA test. This analysis involved one between-subjects factor and one within-subjects factor. The between-subjects factor was reading ability, and the levels of that factor were high proficiency and low proficiency. The within-subjects factor was the use of organizational devices, and the levels of this factor were organizational devices being present and not present. This statistical procedure was performed to test the following three effects:

1) The main effect of reading proficiency: The test for the main effect of reading proficiency was used to evaluate whether participants with high reading proficiency developed more coherent mental representations than those with low reading proficiency, regardless of whether organizational devices were present.

2) The main effect of organizational devices: The test for the main effect of organizational devices evaluated whether there was a difference in effect between the inclusion and exclusion of organizational devices.

3) The interaction between reading proficiency and use of an organizational device: The test for this interaction evaluated whether the differences in effects between the inclusion and exclusion of organizational devices were the same for both reading groups. All of the statistical tests used an alpha level of .05 as the level of significance.

\section{Results}

This study's research questions probe the influence of well-structured electronic texts on ESL learners' reading comprehension. To address the research questions, the participants' scores on 12 relevant multiple-choice and MOMID questions were closely examined. These questions required successful recognition of the important ideas within individual units and the relationships among those units, which involved selecting and extracting important ideas from individual units and integrating the selected information into a coherent structure. Each question was scored 1 for a correct answer and 0 for an incorrect answer; thus, the total scores could range from 0 to 12 . Table 4 presents the results of the paired samples $t$-test conducted to examine the effect of the inclusion or exclusion of organizational devices.

As Table 4 shows, the participants' $(N=40)$ comprehension improved significantly in the 12 designated questions when organizational devices were included $(t=9.49, p<0.001)$. The mean for all participants' scores on the comprehension questions was 4.95 for the less-structured electronic text, compared to 8.45 for the well-structured electronic text. The standard deviation was 1.97 for the less-structured electronic text and 1.84 for the well-structured electronic text.

Table 4. Paired samples t-test results for participants' scores on reading comprehension questions $(\mathrm{N}=40)$

\begin{tabular}{lllllll}
\hline \multicolumn{5}{l}{ Without organizational devices } & \multicolumn{4}{l}{ With organizational devices } \\
\hline Test & $M$ & $S D$ & $M$ & $S D$ & $t$ & $p$ \\
& & & & & & \\
Comprehension questions & 4.95 & 1.97 & 8.45 & 1.84 & $9.49<.001$ \\
\hline
\end{tabular}

Both proficient and less-proficient participants performed significantly better in responding to questions for the well-organized and structured electronic text that included some organizational devices, as Figure 3 demonstrates. 


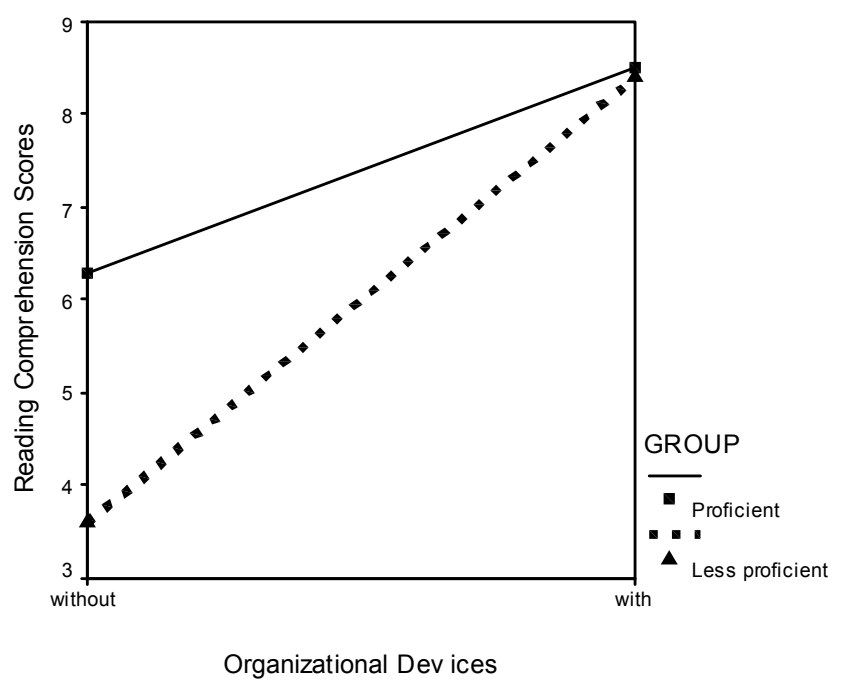

Figure 3. Improvement in reading comprehension for proficient and less-proficient readers

In fact, 30 of 40 participants performed better on the tests associated with the well-structured electronic text. Of the remaining 10 participants, four scored the same under both conditions, and six performed better with the less-structured electronic text; however, for the latter group, the differences in performance were marginal, with an average difference of just two points better.

With respect to the interaction effects between reading ability and the presence or absence of organizational devices on participants' reading comprehension, participants' responses on the two employed tests were examined. Table 5 presents means and standard deviations of participants' scores on the multiple choice test, and Table 6 presents the results of the two-way ANOVA. Table 7 presents the means and standard deviations of participant's scores on the mapping and details tests, and Table 8 presents the results of the two-way ANOVA.

Table 5 shows the means and standard deviations of the participants' scores on the multiple choice tests. As can be seen, the mean of proficient readers with the less structured hypertext was 10.30 and 11.05 with the well-structured electronic texts. The standard deviation was 2.22 with the less-structured hypertext and 1.76 with the well structured electronic texts. By contrast, the less proficient readers' mean for less-structured electronic texts was 6.10 and 9.45 for well-structured electronic texts. Their standard deviations were 1.44 with the less-structured and 1.90 with the well-structured electronic texts.

Table 5. Means and standard deviations of multiple choice test scores by proficiency level and use of device $(\mathrm{n}=20)$

\begin{tabular}{llllll}
\hline & \multicolumn{2}{l}{ Organizational Device } & & \\
& No & & Yes & \\
\hline & $M$ & $S D$ & $M$ & $S D$ & Marginal \\
\hline Proficiency Level & & & & & \\
Proficient & 10.30 & 2.22 & 11.05 & 1.76 & 10.68 \\
Less proficient & 6.10 & 1.44 & 9.45 & 1.90 & 7.78 \\
Marginal & 8.20 & & 10.25 & & \\
\hline
\end{tabular}

Table 6 presents results of the two-way ANOVA. The effect of the interaction between proficiency level and use of the organizational devices (well-structured electronic environment) was highly significant $\left(\mathrm{F}_{1,38}=21.35, p<\right.$ 0.0005). Because of the presence of a significant interaction, a graph of the interaction was examined before interpreting the main effects. A graph of the interaction is shown in Figure 4. 
Table 6. Results of analysis of variance on multiple choice test scores $(\mathrm{N}=40)$

\begin{tabular}{lrrrrc}
\hline Source & \multicolumn{1}{c}{$S S$} & $d f$ & \multicolumn{1}{c}{$M S$} & $F$ & \multicolumn{1}{c}{$p$} \\
\hline Between subjects & & & & & \\
$\quad$ Proficiency & 168.20 & 1 & 168.20 & 31.68 & \\
$\quad$ Error & 201.75 & 38 & 5.18 & & \\
& & & & & $<0005$ \\
Within subjects & & & & & $<0.0005$ \\
$\quad$ Device & 84.05 & 1 & 84.05 & 53.10 & \\
$\quad$ Device X proficiency & 33.80 & 1 & 33.80 & 21.35 & \\
$\quad$ Error & 60.15 & 38 & 1.58 & & \\
\hline
\end{tabular}

As can be seen in Figure 3, the interaction is ordinal. Therefore, it is still appropriate to interpret the main effects. The main effect for the inclusion of the organizational devices was highly significant $\left(\mathrm{F}_{1,38}=53.10, p<0.0005\right)$. Regardless of proficiency level, all students performed better when reading well-structured hypertext that had some organizational devices included $(M=10.25)$ than when reading the less structured electronic texts that had no organizational devices included $(\mathrm{M}=8.20)$. However, as shown in Figure 4, the structured electronic texts had a stronger effect on the performance of less proficient readers. The main effect for proficiency level was also significant $\left(\mathrm{F}_{1,38}=31.68, p<0.0005\right)$.

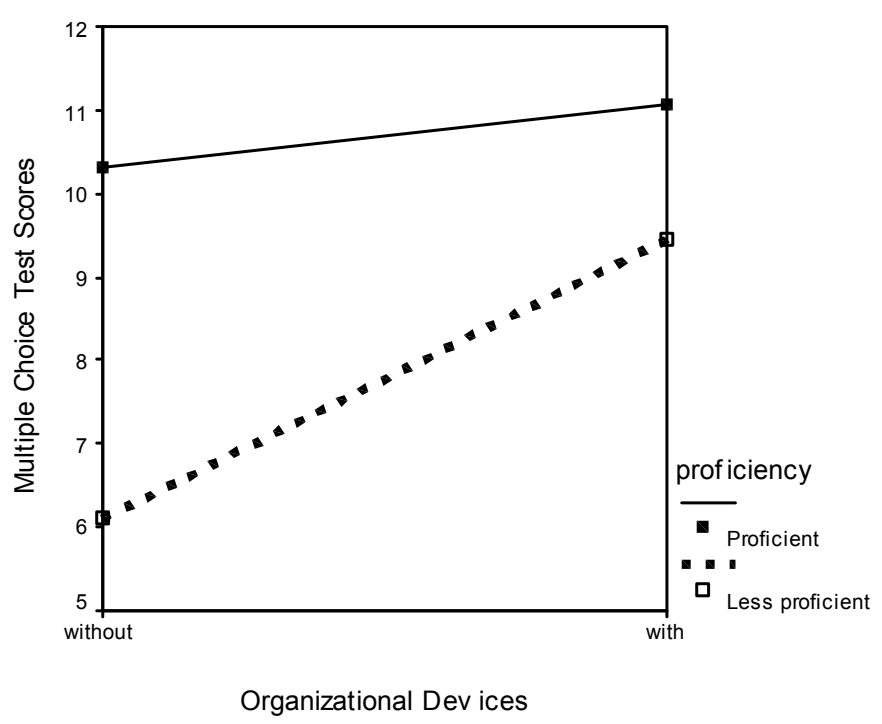

Figure 4. Interaction between presence or absence of organizational devices and reading proficiency: multiple choice test

Table 7 presents the means and standard deviations of participants' scores on the mapping main ideas and details test. It shows that the mean of proficient readers reading the less-structured electronic texts was 6.60 , which was close to the mean of 6.55 based on their reading of the well structured electronic texts. Their standard deviations were 1.88 with less-structured hypertext and 1.85 with well structured electronic texts. By contrast, the less proficient readers' mean when reading the less-structured electronic texts was 4.60 , and it was calculated at 7.60 when reading the well structured electronic texts. Their standard deviations were 1.64 with less structured and 1.79 with well-structured electronic texts. 
Table 7. Means and standard deviations of mapping test scores by proficiency level and use of device $(\mathrm{N}=40)$ organizational device

\begin{tabular}{|c|c|c|c|c|c|}
\hline \multirow[b]{4}{*}{ Proficiency } & \multicolumn{4}{|c|}{ Organizational Device } & \multirow[b]{3}{*}{ Marginal } \\
\hline & \multicolumn{2}{|c|}{ No } & \multicolumn{2}{|c|}{ Yes } & \\
\hline & $M$ & $S D$ & $M$ & $S D$ & \\
\hline & & & & & \\
\hline Proficient & 6.60 & 1.88 & 6.55 & 1.85 & 6.58 \\
\hline Less & & & & & \\
\hline proficient & 4.60 & 1.64 & 7.60 & 1.79 & 6.10 \\
\hline Marginal & 5.60 & & 7.08 & & \\
\hline
\end{tabular}

Table 8 presents the results of the two-way ANOVA. The effect of the interaction between reading proficiency level and use of the organizational devices was highly significant $\left(\mathrm{F}_{1,38}=38.03, p<0.0005\right)$. Because of the presence of a significant interaction, a graph of the interaction was examined before interpreting the main effects (see Figure 3).

Table 8. Results of analysis of variance on mapping test scores $(\mathrm{N}=40)$

\begin{tabular}{lccccc}
\hline Source & $S S$ & $D f$ & $M S$ & $F$ & $p$ \\
\hline Between subjects & 1 & 1 & 4.51 & 0.87 & 0.36 \\
$\quad$ Proficiency & 196.88 & 38 & 5.18 & & \\
$\quad$ Error & & & & \\
& & & & 35.58 & $<0.0005$ \\
Within subjects & 43.51 & 1 & 43.51 & 38.03 & $<0.0005$ \\
$\quad$ Device & 46.51 & 1 & 46.51 & & \\
$\quad$ Device X proficiency & 46.48 & 38 & 1.22 & & \\
$\quad$ Error & & & & & \\
\hline
\end{tabular}

As can be seen in Figure 5, the interaction is disordinal. Therefore, interpretation of the main effects is not appropriate. Without the organizational devices, the more proficient readers performed at a higher level than the less proficient readers. However, when using the organizational devices, the more proficient readers performed at a slightly lower level than the less proficient readers. Stated in another way, the use of the organizational devices had virtually no effect on the performance of the more proficient readers, but had a strong beneficial effect on the performance of the less-proficient readers. When considering the results for both the multiple choice and mapping tests, it can be seen that the well-structured electronic texts had a greater positive impact on the performance of the less-proficient readers. 


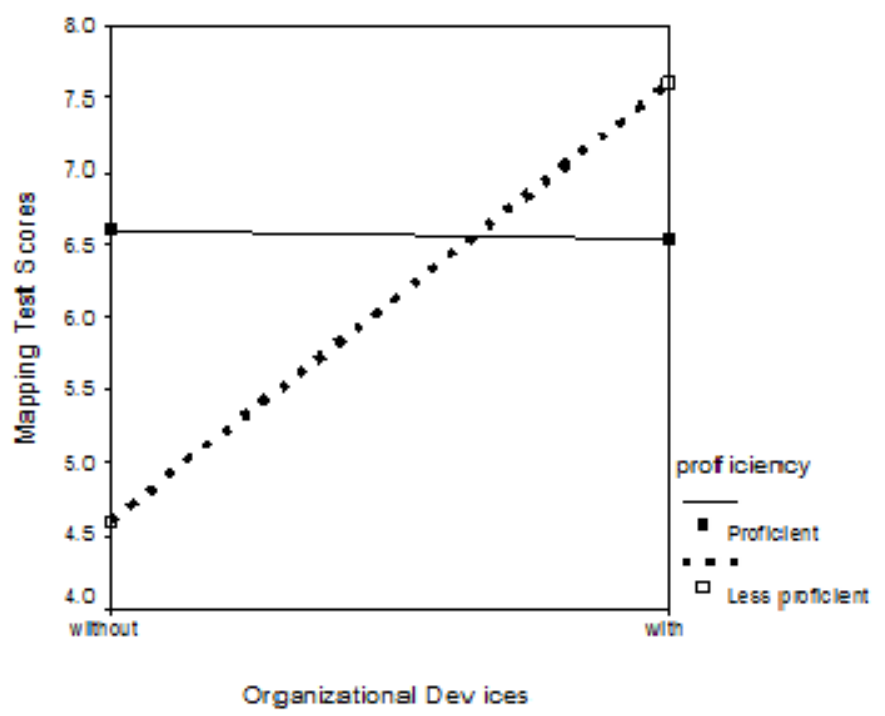

Figure 5. Interaction between presence or absence of organizational devices and reading proficiency: mapping test

Table 9 presents the correlation between the continuous TOEFL reading scores (which were used as a measure of reading proficiency) and scores on the multiple choice and mapping main ideas and detail tests. The results shown in Table 7 are consistent with the results of the two-way mixed model ANOVA. It can be seen that in the case of the multiple choice test, the correlation between reading proficiency and scores in the organizational devices absent (less-structured hypertext reading program) condition $(\mathrm{r}=0.78, p<0.01)$ is stronger than the correlation with scores in the organizational devices present (well-structured reading program) condition $(\mathrm{r}=$ $0.42, p<0.01)$. In the case of the mapping test, the contrast is even more striking. The correlation in the organizational devices absent condition is positive and significant $(\mathrm{r}=.545, \mathrm{p}<.01)$ but in the organizational devices present condition the correlation is negative and non-significant $(\mathrm{r}=-0.29, p>0.05)$.

Table 9. Correlation between reading proficiency and tests scorers (multiple choice and mapping main ideas and detail tests)

\begin{tabular}{llllll}
\hline Reading & $\begin{array}{l}\text { MC test no Org. } \\
\text { Devices included }\end{array}$ & $\begin{array}{l}\text { MC test Org. } \\
\text { Devices included }\end{array}$ & $\begin{array}{l}\text { Mapping } \\
\text { Org. } \\
\text { included }\end{array}$ & $\begin{array}{l}\text { test no } \\
\text { Devices }\end{array}$ & $\begin{array}{l}\text { Mapping test Org. } \\
\text { Devices included }\end{array}$ \\
\hline $0.78^{* *}$ & $0.42^{* *}$ & $0.55^{* *}$ & -0.29 \\
& $0.63^{* *}$ & $0.53^{* *}$ & -0.16 \\
& & $0.57^{* *}$ & $0.44^{* *}$ \\
& & & $0.37^{*}$ \\
\hline
\end{tabular}

\footnotetext{
**Correlation is significant at the 0.01 level (2-tailed).
}

* Correlation is significant at the 0.05 level (2- tailed).

\section{Discussion}

The results of this study demonstrate that the participants comprehended the well-structured electronic text better. Regarding the effect sizes on reading comprehension, Cohen's $f(1.50)$ was very large, which suggests that the well-structured electronic text made a considerable difference in reading comprehension. In this case, the participants scored higher on questions that assessed their comprehension when they read the well-structured electronic text.

This result presumably occurred because the included organizational devices contributed to successful comprehension by fostering macrostructural construction and organization - the two levels of macrostructural 
processing needed for comprehension. As discussed in the literature review, construction involves selecting and extracting important information in individual units, and organization involves organizing the selected information into a unified representation. In the well-structured electronic text, the organizational devices made the important information in each unit more salient; therefore, the participants were able to identify information when asked about it and then recognize the interrelationships among its parts (macrostructural construction). These organizational devices also helped the participants to organize the macrostructural representation of the electronic text units into a coherent representation.

The positive effect of including organizational devices suggests that ESL learners, especially less-proficient ESL readers, need mathemagenic aids to orient them, show them what is important and relevant, and overtly display the overall structure of instructional electronic texts. These learners typically lack the necessary skills to register, select, and identify important textual information; interrelate and organize this information into a coherent whole; and derive a higher-order structure of the text. Thus, in less-structured reading environments, having to devote mental resources to figuring out the text's structure often comes at the expense of the primary task of successfully comprehending the text's content.

These results are in line with the literature. As Foltz (1992) and Lacroix (1999) concluded, the structure of an electronic text and the explicit representation of the text's underlying structure influence macrostructural processing. In particular, Lacroix (1999) found that the inclusion of organizational devices such as local and global headings positively affects readers' comprehension. In Lacroix's (1999) study, these devices made the participants sensitive to important information within each unit, which they then included into their summaries (macrostructural construction), and enabled the participants to represent the electronic text in a more unified form (macrostructural organization). The findings of the present study also reflect those of Al-Seghayer (2007), who showed that the participants were able to construct appropriate mental representations of an electronic text due to the provision of structural devices, as reflected in their ability to identify the main ideas and supporting details. Furthermore, this study's results are comparable to those reported by Abdi (2012), who demonstrated that exposing ESL readers to electronic texts supported their reading comprehension.

\section{Implications}

The pedagogical implications of this study for L2 reading comprehension are multifaceted. ESL learners need to be trained to read electronic texts more effectively. Similarly, English teachers need to provide training on electronic text structures before students engage in electronic reading environments. Specifically, instructors should help students acquire specific strategies to know where they are and what to do next in an electronic document, recognize relationships between electronic text units, and build a coherent representation of the overall electronic content.

When readers are left to their own devices, they may wander at random through electronic text, making incoherent jumps among text units. Thus, ESL learners need to be taught how to use organizational devices as a framework for reading and, in particular, to use electronic text structure as a reading strategy. As ESL readers need to make decisions concerning their reading path and remain focused on their reading purposes, self-monitoring is also an essential electronic reading component or skill they must learn.

At the same time, ESL instructors should provide engaging electronic reading materials and design interesting tasks so that students can construct meaning when reading electronic text. In particular, instructors should provide and develop well-organized electronic text for ESL learners - especially less-proficient readers, as Salmerón et al. (2005) indicated - because they comprehend better by following a highly coherent reading order. Providing scaffolding to orient learners to the task is also important to the successful implementation and integration of electronic reading in the classroom (Yang, 2001).

With respect to technological implications, designers of reading instruction should develop and embed interactive tools that enable ESL readers to interact with the electronic text. For example, readers should have the options to insert or delete content, mark passages by underlining or highlighting, and insert comments. Designers should also use interactive organizational devices to attract and engage readers' attention and use a flexible format system that includes dynamic media and allows users to modify both the layout and interactive features of the electronic text. Just as importantly, designers need to include organizational devices that alert readers to important information locally and help them identify relationships among electronic text units and organize those units into a coherent representation while reducing the cognitive requirements for processing electronic text.

\section{Future Research Directions}

The results of this study also suggest several avenues for future research. Regarding pedagogy, researchers 
should explore domains of the new literacy skills demanded by the electronic reading environment, including identifying problems and questions, locating information from multiple electronic text format resources, critically evaluating information online, synthesizing information online, and communicating and exchanging information online. An interesting and related line of research would be examining the dual metacognitive processes of evaluation and regulation involved in evaluating the relevance and accuracy of multiple electronic sources. Similarly, researchers could experiment with increasing readers' control over electronic reading material and allow L2 readers to take an active role in their own reading processes to examine whether greater involvement facilitates the readers' comprehension of electronic text.

With respect to the influence of organizational devices, future studies could qualitatively explore how ESL readers perceive the facilitative effect of well-structured electronic texts on their reading comprehension. Researchers could also interview ESL readers about whether they use and take advantage of available organizational devices.

\section{Limitations}

This study has several methodological limitations. First, I measured ESL electronic reading comprehension using multiple-choice and MOMID tests. Alternative assessment techniques that tap different aspects of electronic reading command, including oral and written protocols (such as cued recall and summary) and delay testing, could further improve this measurement. Second, the study did not precisely measure the five components of electronic reading comprehension: (a) solving problems and answering questions, (b) location, (c) analysis, (d) synthesis, and (e) communication. Third, this study was conducted using static computer screens and page-fidelity text. To counter this limitation, newer electronic text formats (reflowable text and enhanced electronic text features) should be used to examine their impact on L2 reading comprehension of electronic text. Finally, the small sample size limited the statistical power of this study and its findings. To better understand L2 reading comprehension of electronic text, future studies should adopt research design components that address these limitations.

\section{Conclusion}

This study identifies factors that facilitate L2 reading comprehension in electronic reading environments - namely, technical features that display the physical layout and organization of a text in a computerized reading program. The results suggest a relationship between ESL readers' mental reconstruction of a text's structure and their reading comprehension. In this relationship, levels of electronic text structure have a strong impact on L2 reading comprehension. Accordingly, in well-structured electronic reading environments, L2 readers can construct a solid mental representation of the text's structure, which in turn increases their L2 reading comprehension.

These findings illustrate the potential effect of text structures and discourse organization as well as the role of knowledge of these features on proficient and less-proficient ESL readers' electronic text comprehension. However, this study only represents a preliminary empirical effort to examine the comparative efficacy of well-structured and less-structured electronic reading environments in improving L2 reading comprehension and determine whether L2 reading proficiency levels influence electronic reading comprehension. Further research is needed to develop a thorough understanding of how to design electronic texts to facilitate L2 reading comprehension as well as confirm this study's findings. Future studies should also examine other variables that influence how ESL readers process electronic texts.

\section{References}

Abdi, R. (2012). The effect of using hypertext materials on reading comprehension ability of EFL learners. Procedia- Social and Behavioral Sciences, 83(issue), 557-562.

Alexander, P. A., \& Jetton, T. L. (2000). Learning from text: A multidimensional and developmental perspective. In M. L. Kamil, P. Mosenthal, P. D. Pearson, \& R. Barr (Eds.), Handbook of reading research, (volume III, pp. 285-310). Mahwah, NJ: Erlbaum.

Al-Seghayer, K. (2007). The role of organizational devices in ESL readers' construction of mental representations of hypertext content. CALICO Journal, 24(3), 531-559.

Al-Seghayer, K. (2014). The impact of gender and reading proficiency level on online reading strategies employed by EFL learners. Journal of Educational Sciences of King Saud University, 6(2), 493-509.

Alshumaimeri, Y., \& Almasri, M. (2012). The effects of using WebQuests on reading comprehension performance of Saudi EFL students. The Turkish Online Journal of Educational Technology, 11(4), 295-306. 
Balajithy, E. (1990). Hypertext, hypermedia, and metacognition: Research and instructional implications. Reading, Writing, and Learning Disabilities, 6(2), 183-202. https://doi.org/10.1080/0748763900060207

Balcytiene, A. (1999). Exploring individual processes of knowledge construction with hypertext. Instructional Science, 27(3-4), 303-328. https://doi.org/10.1007/BF00897324

Britt, M. A., Rouet, J. F., \& Braasch, J. (2013). Documents as entities: Extending the situation model theory of comprehension. In M. A. Britt, S. R. Goldman, \& J. F. Rouet (Eds.), Reading - From words to multiple texts (pp. 160-179). New York: Routledge.

Castek, J., Leu, D. J., Jr., Coiro, J., Gort, M., Henry, L. A., \& Lima, C. (2007). Developing new literacies among multilingual learners in the elementary grades. In L. Parker (Ed.), Technology-mediated learning environments for young English learners: Connections in and out of school (pp. 111153). Mahwah, NJ: Erlbaum.

Chiang, M. (2016). Utilizing electronic reading device (Kindle) in English as foreign language reading class. Sino-US English Teaching, 13(4), 233-244.

Coiro, J., \& Dobler, E. (2007). Exploring the online reading comprehension strategies used by sixth-grade skilled readers to search for and locate information on the Internet. Reading Research Quarterly, 42(2), 214-257. https://doi.org/10.1598/RRQ.42.2.2

Coiro, J. (2003). Reading comprehension on the Internet: Expanding our understanding of reading comprehension to encompass new literacies. The Reading Teacher, 56(5), 458-64.

Foltz, P. (1996). Comprehension, coherence, and strategies in hypertext and linear text. In J. Rouet, J. Levonen, \& R. Spiro (Eds.), Hypertext and cognition (pp. 109-136). Mahwah, NJ: Lawrence Erlbaum.

Kim, H. (2007). The effects of computer-assisted reading instruction on reading skills and vocabulary learning. Multimedia-Assisted Language Learning, 10(3), 27-50.

Hofman, R., \& Oostendorp, H. (1999). Cognitive effects of a structural overview in a hypertext. British Journal of Educational Technology, 3(2), 129-140. https://doi.org/10.1111/1467-8535.00101

Kintsch, W., \& Van Dijk, T. (1978). Toward a model of text comprehension and production. Psychological Review, 85(5), 363-394. https://doi.org/10.1037/0033-295X.85.5.363

Kintsch, W. (1998). Comprehension: A paradigm for cognition. Cambridge: Cambridge University Press.

Leu, D. J., Zawilinski, L., Castek, J., Banerjee, M., Housand, B., Liu, Y., \& O’Neil, M. (2007). What is new about the new literacies of online reading comprehension? In A. Berger, L. Rush, \& J. Eakle (Eds.), Secondary school reading and writing: What research reveals for classroom practices (pp. 37-68). Chicago, IL: National Council of Teachers of English.

Lee, Y. (1989). Effects of learning style and instructional cues and achievement and learning interactivity in a hypermedia instructional system (Unpublished doctoral dissertation). Purdue University, West Lafayette, IN.

Leidig, P. (1992). The relationship between cognitive styles and mental maps in hypertext assisted learning (Unpublished doctoral dissertation). Virginia Commonwealth University, Richmond, VA.

Leu, D. J., Coiro, J., Castek, J., Hartman D., Henry, L. A., \& Reinking, D. (2008). Research on instruction and assessment in the new literacies of online reading comprehension. In C. C. Block, \& S. R. Parris (Eds.), Comprehension instruction: Research-based best practices (pp. 321-341). New York: The Guildford Press.

Liu, Y. (2015). Enhancing L2 digital reading for EFL learners. English Teaching \& Learning, 39(2), 33-64.

McNamara, D., Kintsch, E., Songer, N., \& Kintsch, W. (1996). Are good texts always better? Interactions of text coherence, background knowledge, and levels of understanding in learning from text. Cognition and Instruction, 14(1), 63-182. https://doi.org/10.1207/s1532690xci1401_1

Nielsen, J. (1989). The matters that really matter for hypertext usability. Proceedings of the ACM Conference on Hypertext '89 (pp. 239-248). New York: ACM. https://doi.org/10.1145/74224.74244

Pookcharoen, S. (2009). Metacognitive online reading strategies among Thai EFL university students (Unpublished doctoral dissertation). Indiana University, Bloomington, IN.

Park, J., Yang, J., \& Hsieh, Y. (2014). University level second language readers' online reading and comprehension strategies. Language Learning \& Technology, 18(3), 148-172. 
Perfetti, C. A., Rouet, J. F., \& Britt, M. A. (1999). Toward a theory of documents representation. In H. Van Oostendorp, \& S. R. Goldman (Eds.), The construction of mental representations during reading (pp. 99-122). Mahwah, NJ: Lawrence Erlbaum Associates.

Salkhord, S., Gorjian, B., \& Pazhakh, A. (2013). The effect of digital stories on reading comprehension: an internet-based instruction for Iranian EFL Young learners. International Journal of Language Learning and Applied Linguistics World, 4(4), 111-124.

Salmerón, L., Cañas, J. J., Kintsch, W., \& Fajardo, I. (2005). Reading strategies and hypertext comprehension. Discourse Processes, 40(3), 171-191. https://doi.org/10.1207/s15326950dp4003_1

Songsienghai, T. (2010). Strategies in reading online and printed academic text of English major students of Srinakharinwirot University (Unpublished MA thesis). Srinakharinwirot University, Bangkok.

Spiro, R. J., Coulson, R. L., Feltovich, P. J., \& Anderson, D. (2004). Cognitive flexibility theory: Advanced knowledge acquisition in ill-structured domains. In R. B. Ruddell (Ed.), Theoretical models and processes of reading (5th ed.) (pp. 602-616). Newark, DE: International Reading Association.

Van Dijk, T., \& Kintsch, W. (1983). Strategies of discourse comprehension. Hillsdale, NJ: Lawrence Erlbaum.

Yang, S. C. (2001). Language learning on the World Wide Web: An investigation of EFL learners' attitude and perceptions. Journal of Educational Computing Research, 24(2), 155-181. https://doi.org/10.2190/VDJC-FGTQ-79FH-M615

Yanguas, I. (2009). Multimedia glosses and their effect on L2 text comprehension and vocabulary learning. Language Learning \& Technology, 13(2), 48-67.

Zwaan, R., \& Brown, C. (1996). The influence of language proficiency and comprehension skill on situation model construction. Discourse Processes, 21(3), 289-327. https://doi.org/10.1080/01638539609544960

\section{Copyrights}

Copyright for this article is retained by the author(s), with first publication rights granted to the journal.

This is an open-access article distributed under the terms and conditions of the Creative Commons Attribution license (http://creativecommons.org/licenses/by/4.0/). 